\title{
Nitric oxide releasing nanoparticles for treatment of Candida albicans burn infections
}

\author{
Chitralekha Macherla ${ }^{1}$, David A. Sanchez ${ }^{2,3}$, Mohammed S. Ahmadi ${ }^{1,4}$, Ernestine M. Vellozzi ${ }^{1}$, \\ Adam J. Friedman ${ }^{5}$, Joshua D. Nosanchuk ${ }^{2,3}$ and Luis R. Martinez 1,2,3 *
}

${ }^{1}$ Department of Biomedical Sciences, Long Island University, Brookville, NY, USA

2 Divisions of Infectious Diseases, Department of Medicine, Albert Einstein College of Medicine, Bronx, NY, USA

${ }^{3}$ Department of Microbiology and Immunology, Albert Einstein College of Medicine, Bronx, NY, USA

${ }^{4}$ Adelphi University, Garden City, NY, USA

${ }^{5}$ Divisions of Dermatology, Department of Medicine, Albert Einstein College of Medicine, Bronx, NY, USA

\section{Edited by:}

Helio K. Takahashi, Universidade

Federal de Sao Paulo, Brazil

\section{Reviewed by:}

Jose M. Diaz-Minguez, Microbiologia

y Genetica University of Salamanca CIALE, Spain

Simon Andrew Johnston, University

of Birmingham, UK

*Correspondence:

Luis R. Martinez, Long Island

University, Post 720 Northern

Boulevard, Pell Hall/Life Science

Building, Room 347, Brookville, NY

11548-1300, USA.

e-mail: luis.martinez-torres@liu.edu
Candida albicans is a leading fungal cause of burn infections in hospital settings, and sepsis is one of the principle causes of death after a severe burn. The prevalence of invasive candidiasis in burn cases varies widely, but it accounts for $3-23 \%$ of severe infection with a mortality rate ranging from 14 to $70 \%$. Therefore, it is imperative that we develop innovative therapeutics to which this fungus is unlikely to evolve resistance, thus curtailing the associated morbidity and mortality and ultimately improving our capacity to treat these infections. An inexpensive and stable nitric oxide (NO)-releasing nanoparticle (NO-np) platform has been recently developed. NO is known to have direct antifungal activity, modulate host immune responses and significantly regulate wound healing. In this study, we hypothesized that NO-np would be an effective therapy in the treatment of $C$. albicans burn infections. Using a murine burn model, NO-np demonstrated antifungal activity against $C$. albicans in vivo, most likely by arresting its growth and morphogenesis as demonstrated in vitro. NO-np demonstrated effective antimicrobial activity against yeast and filamentous forms of the fungus. Moreover, we showed that NO-np significantly accelerated the rate of wound healing in cutaneous burn infections when compared to controls. The histological evaluation of the affected tissue revealed that NO-np treatment modified leukocyte infiltration, minimized the fungal burden, and reduced collagen degradation, thus providing potential mechanisms for the therapeutics' biological activity. Together, these data suggest that NO-np have the potential to serve as a novel topical antifungal which can be used for the treatment of cutaneous burn infections and wounds.

Keywords: nitric oxide, nanoparticles, burn healing, collagen, Candida albicans

\section{INTRODUCTION}

Sepsis is one of the leading causes of death after a severe burn injury. The rate of microbial infection is estimated to range from 30 to $63 \%$ among all burn victims admitted to burn centers, with the incidence also associated with the severity of injury and the duration of hospital stay (Holzheimer and Dralle, 2002). Microorganisms responsible for sepsis are usually bacteria, including Pseudomonas aeruginosa and Staphylococcus aureus; however, Candida spp., of which C. albicans is the most common, are etiologic in $\sim 8 \%$ of all cases (Santucci et al., 2003). Burn wound colonization and local infection with Candida spp., can progress to systemic disease. The prevalence of invasive candidiasis in burn cases accounts for as much as $\sim 23 \%$ of severe infections (Holzheimer and Dralle, 2002) with mortality rates ranging from 14 to $70 \%$ (Holzheimer and Dralle, 2002; Eggimann et al., 2003a).

We recently developed and characterized an inexpensive and stable nitric oxide (NO)-releasing nanoparticle (NO-np) platform using nanotechnology based on a silane hydrogel (Eggimann et al., 2003b). This technology has the potential to serve as a novel, easily applied, topical delivery system for antimicrobials, such as NO, which can be used for the treatment of complex cutaneous infections and wounds. In both physiologic and pathologic conditions, NO maintains skin homeostasis by regulating circulation, ultraviolet-mediated melanogenesis, and sunburn erythema, which all participate in the maintenance of the skin as a protective barrier against microorganisms (Frank et al., 2002). Notably, NO also modulates immune responses and is a significant regulator of wound healing (Soneja et al., 2005; Mowbray et al., 2008). In fact, the simplicity and the stability of NO-np for use in sustained delivery of NO make the nanoparticles a very attractive treatment modality for many conditions. This is supported by our previous work which demonstrated potent NO-np efficacy in vitro (Friedman et al., 2011) and in vivo against multi-drug resistant bacteria which currently challenge many of the successful antibiotic therapies (Han et al., 2009; Martinez et al., 2009; Mihu et al., 2010; Schairer et al., 2012). Ghaffari et al. (2006) has shown that NO is effective against $C$. albicans even though the fungus possesses a highly inducible NO defense mechanism (Ullmann et al., 2004; Tillmann et al., 2011). Based on our previous work and the fact that $\mathrm{NO}$ easily transits most if not all biological barriers, we have 
hypothesized that NO-np would be fungicidal for C. albicans in an in vivo setting. Hence, NO-np could be an effective means for treating burned infections caused by this fungus. To validate this hypothesis, we have investigated the biological impact of NO-np on C. albicans using a murine burn infection model.

\section{MATERIALS AND METHODS CANDIDA ALBICANS}

Candida albicans SC5314 was obtained from M. Ghannoum (Cleveland, OH, USA). Unless otherwise stated, the isolate was grown in yeast extract, peptone, and dextrose (YPD) broth (Difco Laboratories) containing $10 \mathrm{~g} / \mathrm{L}$ yeast extract, $10 \mathrm{~g} / \mathrm{L}$ peptone, and $20 \mathrm{~g} / \mathrm{L}$ glucose and incubated for $24 \mathrm{~h}$ at $30^{\circ} \mathrm{C}$ in a shaker set at $150 \mathrm{rpm}$ (IKA KS 4000, Cole-Parmer, Vernon Hills, IL, USA; to early stationary phase).

\section{SYNTHESIS OF NO-np}

A hydrogel/glass composite was synthesized using a mixture of tetramethyl orthosilicate, polyethylene glycol, chitosan, glucose, and sodium nitrite in a $0.5 \mathrm{~mm}$ sodium phosphate buffer $(\mathrm{pH}$ 7 ). The nitrite was reduced to NO within the matrix with thermally generated electrons from glucose. After the redox reaction, the ingredients were combined and dried using a lyophilizer, and which resulted in a fine powder comprised of nanoparticles containing NO. The NO-np remains stable in this form for more than 1 year at room temperature. Once exposed to an aqueous environment, the hydrogel properties of the composite allow for an opening of the water channels inside the particles, facilitating the release of the trapped NO overextended time periods. Nanoparticles (np) were also prepared without the addition of NO, and served as a control.

\section{SUSCEPTIBILITY OF C. ALBICANS SC5314 TO NO-np}

To determine the impact of the NO-np on C. albicans, $1 \mathrm{~mL}$ of YPD broth was inoculated with a $24 \mathrm{~h}$ colony of the fungus grown on YPD agar. One hundred $\mu \mathrm{L}$ of $C$. albicans broth suspension was inoculated in each well of a 200 -well plate, containing $100 \mu \mathrm{L}$ of YPD broth with either NO-np or np $(5 \mathrm{mg} / \mathrm{mL}$; Nitric oxide kinetics release from nanoparticles: Peak state: $18.75 \mathrm{nM}$; Steady state: $12.5 \mathrm{nM}$ ). The inoculated plate was then incubated for $24 \mathrm{~h}$ at $37^{\circ} \mathrm{C}$. Controls included wells containing yeast suspension alone, and yeast cells in YPD broth containing np. Growth was assessed every 30 min using a microplate reader (Bioscreen C, Growth Curves USA, Piscataway, NJ, USA) set at an OD of $600 \mathrm{~nm}$.

\section{IN VIVO BURN INJURY AND INFECTION MODEL AND NO-np TREATMENT}

To investigate the antifungal efficacy of NO-np in C. albicans induced burn infections, female Balb/c mice (6-8 weeks; National Cancer Institute, Frederick, MD, USA) were anesthetized (ketamine-xylazine cocktail), their back hair removed, and their exposed skin cleansed with an application of iodine. Five-mm diameter burn injuries were created applying a 60 s-heated brass bar for $45 \mathrm{~s}$. Immediately after injury, C. albicans was inoculated onto the burned tissue using a $10^{7}$ cell suspension of the yeast prepared in PBS. Animals were individually housed to prevent crossed infection. On day 1 after infection, $5 \mathrm{mg}$ of NO-np or np powder was then applied. Applications were similarly performed on days 3 and 5 after injury. Untreated, injured mice were used as additional controls. To monitor healing, photographs were taken daily. Also, a caliper was used to blindly measure the burn diameter of the injury on a daily basis, and was performed by two independent investigators. Three and 7 days after infection, mice were euthanized and tissue biopsies were taken.

\section{CFU DETERMINATIONS}

At days 3 and 7 after $C$. albicans infection, wound tissues were excised and homogenized in sterile PBS. Samples were plated on YPD agar and fungal colony counts were determined. The results were normalized by tissue weights.

\section{HISTOLOGICAL EXAMINATIONS}

At days 3 and 7 after wounding, wound tissues were excised from euthanized mice, fixed in $10 \%$ formalin for $24 \mathrm{~h}$, processed, and embedded in paraffin. Four micron vertical sections were fixed to glass slides and subjected to Hematoxylin and Eosin (H\&E), Periodic acid schiff (PAS), Gomori's trichrome, Myeloperoxidase (MPO; day 3), and Iba-1 staining to examine tissue morphology, fungal morphology, collagen deposition, neutrophil infiltration, and macrophage-like cells, respectively. Slides were examined by light microscopy with an Olympus AX70 (Melville, NY, USA) microscope, and images were obtained [QImaging Retiga 1300 digital camera (Burnaby, British Columbia, Canada)] with QCapture Suite V2.46 software (QImaging).

\section{TIME-LAPSE MICROSCOPY}

Candida albicans rapidly undergoes cell division by budding and forms pseudohyphae and hyphae when grown in media supplemented with fetal calf serum (FCS). Hence, the effect of NO-np on C. albicans cell division and morphological transformation was assessed using live cell imaging. Briefly, $10^{6}$ yeasts were plated on a polylysine coated coverslip bottom of MatTek plates. Images were collected for $2 \mathrm{~h}$ at $40 \times$ using a Zeiss Axiovert $200 \mathrm{M}$ inverted microscope with an Axiocam MR camera controlled by the Axio Vision 4.4 software (Carl Zeiss Micro Imaging, NY). This microscope was housed in a Plexiglas box and the temperature was stabilized at $37^{\circ} \mathrm{C}$, using a forced air heater system. The plate lid was kept in place to prevent evaporation, and $5 \% \mathrm{CO}_{2}$ was delivered to a chamber locally over the culture dish. Images were compiled into movies which were then used to analyze the $C$. albicans morphogenesis.

\section{SUSCEPTIBILITY OF FILAMENTOUS C. ALBICANS SC5314 TO NO-np}

To assess the antifungal activity of the NO-np on invasive C. albicans filamentous form, $10^{6}$ yeasts were grown in $100 \mu \mathrm{L}$ of media supplemented with FCS on a 96-well microtiter plates. Plates were incubated for $4 \mathrm{~h}$ at $37^{\circ} \mathrm{C}$ and $5 \% \mathrm{CO}_{2}$. After hyphal formation, $100 \mu \mathrm{L}$ of media supplemented with FCS with either NO-np or np $(5 \mathrm{mg} / \mathrm{mL})$ were added to each well. Then, plates were incubated for $24 \mathrm{~h}$ at $37^{\circ} \mathrm{C}$ and $5 \% \mathrm{CO}_{2}$. Controls included wells containing untreated filamentous fungus. Metabolic activity was measured by 2, 3-bis (2-methoxy-4-nitro-5-sulfophenyl)-5-[(phenylamino) carbonyl]-2H-tetrazolium-hydroxide (XTT) reduction assay. 


\section{XTT REDUCTION ASSAY}

For filamentous C. albicans SC5314, $50 \mu \mathrm{L}$ of XTT salt solution $(1 \mathrm{mg} / \mathrm{mL}$ in PBS) and $4 \mu \mathrm{L}$ of menadione solution $(1 \mathrm{mM}$ in acetone; Sigma) were added to each well. Microtiter plates were incubated at $37^{\circ} \mathrm{C}$ for $5 \mathrm{~h}$. Mitochondrial dehydrogenases in live cells reduce XTT tetrazolium salt to XTT formazan, resulting in a colorimetric change, which was measured in a microtiter reader at $492 \mathrm{~nm}$. Microtiter wells containing heat-killed fungi or only medium but no filamentous $C$. albicans cells were used as negative controls. The percentage of metabolic activity was determined by measuring the optical density of fungi exposed to np or NO-np relative to unexposed biofilms.

\section{STATISTICAL ANALYSIS}

All data were subjected to statistical analysis using GraphPad Prism 5.0 (GraphPad Software, La Jolla, CA, USA). $P$ values were calculated by analysis of variance and were adjusted by use of the Bonferroni correction. $P$ values of $<0.05$ were considered significant.

\section{RESULTS}

\section{NO-np INHIBITS C. ALBICANS GROWTH}

Candida albicans SC5314 growth with and without exposure to $\mathrm{NO}-\mathrm{np}$ was determined in real-time for $24 \mathrm{~h}$ (Figure 1). NO$\mathrm{np}$ significantly reduced fungal growth after $2 \mathrm{~h}$ co-incubation when compared with untreated controls $(P<0.001)$. Notably, $C$. albicans grown with np had significant reductions in fungal growth at $4 \mathrm{~h}$, an effect that is likely due to steric interference with cell to cell contact or communication (e.g., quorum sensing). It is also possible that the chitosan incorporated into the np may offer some degree of antifungal activity; although the concentrations used to generate the np were negligible. When nano-scaled, chitosan has a higher surface to volume ratio, translating into a higher surface charge density, and increased affinity for bacteria and fungi with greater antimicrobial activity (Qi et al., 2004). Therefore at the nano-scale, the concentration used may confer some inhibitory activity. Nevertheless, NO-np significantly impeded growth relative to the $\mathrm{np}$ controls at $>4 \mathrm{~h}$ $(P<0.001)$.

\section{NO-np ENHANCES BURN HEALING IN VIVO}

The effect of NO-np on burn healing in Balb/c mice after C. albicans infection was investigated (Figure 2). The curative process progressed most rapidly in the NO-np-treated mice (Figure 2A), with complete healing in all treated mice within 20 days following burn injury and infection $(P<0.001$; Figure 2B). In contrast, the healing process of untreated or np-treated mice was significantly delayed (Figure 2A), and complete wound closure was not achieved within the 20 days following injury when mice were euthanized (Figure 2B). Notably, animals in the control groups experienced fungal transmission from the burn site to the paws, possibly by scratching of the infected injury (Figure 2C), which is consistent with higher fungal burdens and prolonged infection.

\section{NO KILLED C. ALBICANS IN BURN LESIONS}

The efficacy of NO-np in killing C. albicans in the infected tissue was further explored by examining fungal burdens (Figure 3). At

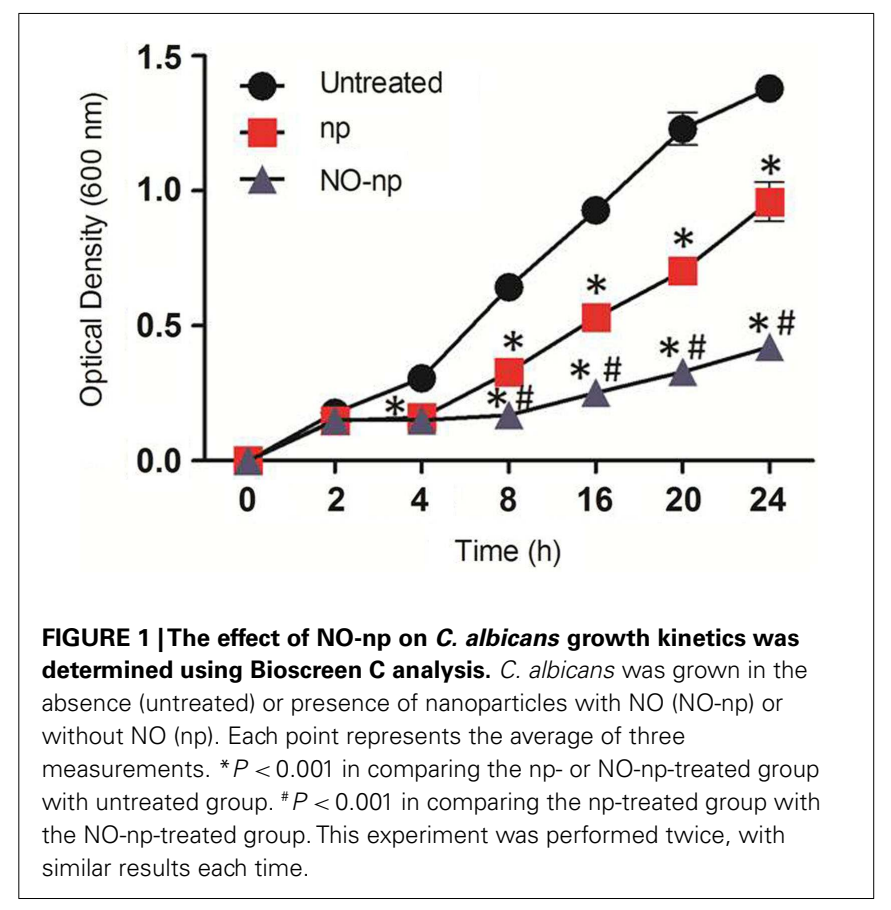

three and 7 days post infection, wounds were excised and plated on YPD agar. C. albicans-infected NO-np-treated burns showed significantly lower fungal burdens when compared to untreated or np-treated wounds $(P<0.01$; Figure $3 \mathrm{~A})$.

Histological examinations (H\&E staining) of day 7 untreated and np-treated $C$. albicans-infected burns revealed numerous pseudohyphal and hyphal forms penetrating into different tissue layers along with extensive cell necrosis (Figure 3B; insets). Tissue sections from the lesions of NO-np-treated C. albicans-infected mice revealed less suppurative inflammation along with increased fibrin deposition and no evidence of fungal hyphal structures in dermis (Figure 3B).

\section{NO-np REDUCES GROWTH AND MORPHOGENESIS}

Time-lapse microscopy was used to examine whether NO-np interferes with C. albicans cell division and morphological transformation (Figure 4A). Untreated control yeasts displayed rapid (12 min) budding formation and morphogenesis. The control np delayed budding and transformation for up to $48 \mathrm{~min}$ post exposure. In contrast, NO-np arrested fungal budding and morphogenesis over the entire $60 \mathrm{~min}$ time course examined. At the $120 \mathrm{~min}$ time point, the untreated group evinced morphological changes consistent with that of candidal pseudohyphal structures while the $\mathrm{np}$ and NO-np-treated groups demonstrated delayed budding or no budding, respectively, without any indication of active filamentation (Figure 4B). In addition, NO-np-treated yeasts displayed a rounded shape characteristic of cellular edema which has been previously observed in studies with multi-drug S. aureus (Martinez et al., 2009). Thus, the results strongly suggest that NO-np can effectively inhibit or delay the onset of pseudohyphal formation. Together, these results suggest that the in vivo findings may in part be due to a reduction in the rate of yeast cell division and morphogenesis. 


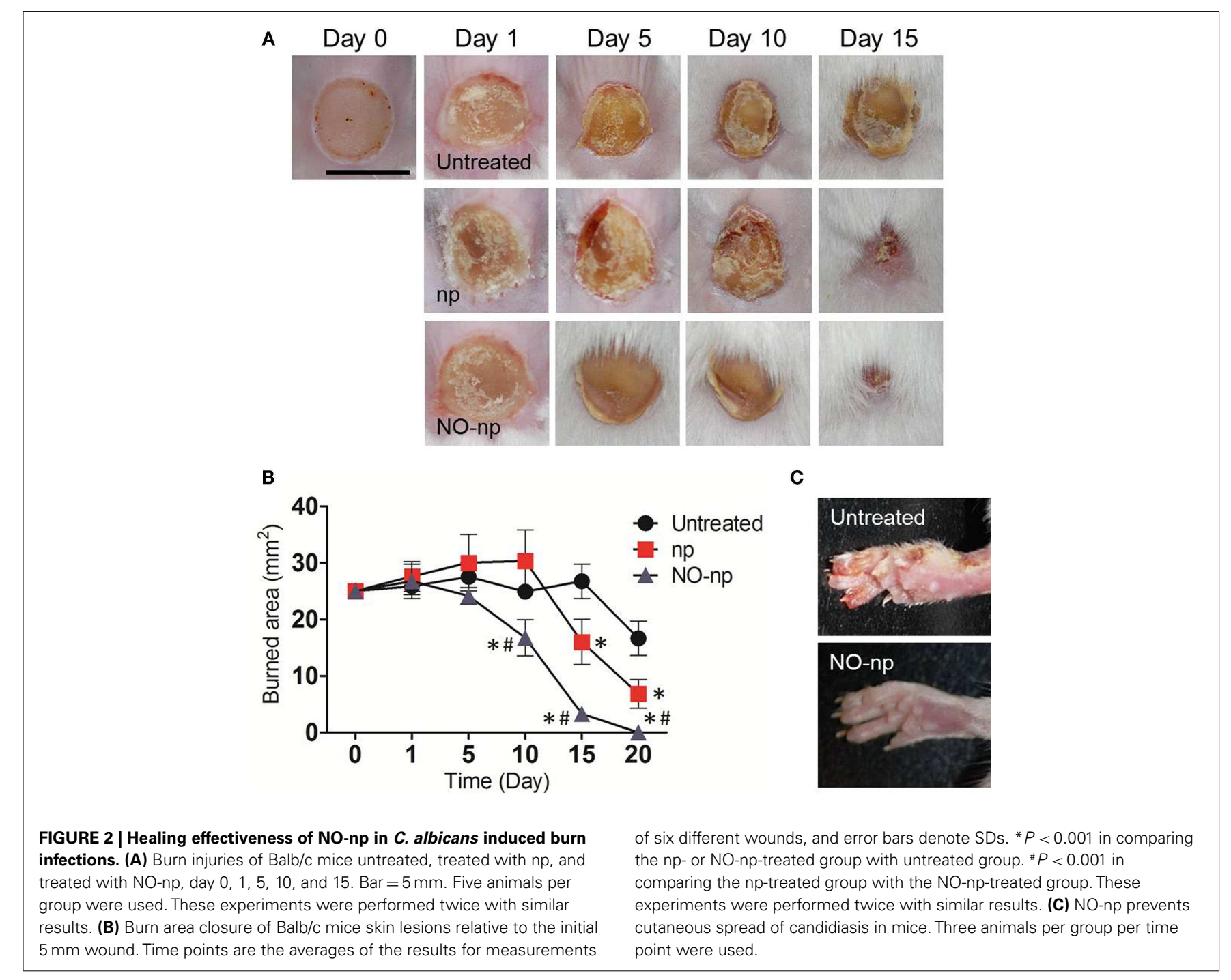

Since the filamentous stage of C. albicans invades tissue and is relevant in pathogenesis, we investigated the antifungal activity of NO-np against the mycelial form of the fungus. XTT reduction assay was utilized to quantify fungal metabolic activity. At $24 \mathrm{~h}$, NO-np significantly reduced the metabolic activity of filamentous C. albicans when compared to untreated $(\sim 65 \% ; P<0.001)$ or $\mathrm{np}(\sim 52 \% ; P<0.001$; Figure $4 \mathrm{C})$. Our findings suggest that NO$\mathrm{np}$ are effective against the tissue invasive filamentous form of $C$. albicans.

\section{NO-np ACCELERATES DEPOSITION AND/OR REDUCES DESTRUCTION OF COLLAGEN IN BURN HEALING DURING CANDIDAL INFECTION}

The mechanisms through which the NO-np accelerates wound healing were further explored by examining the collagen content in burn wounds treated with NO-np (Figure 5). Trichrome staining dyes collagen blue. For each image, quantitative measurement of collagen intensity in 20 representative squares of the same size was performed using Image J software. Collagen content was highest in the infected wounds treated with NO-np (Figure 5A). The dispersed blue stain in these sections indicated a thicker and more mature tissue collagen formation, thus suggesting that NO-np exposure protected the dermal architecture through fungal clearance, and ultimately maintaining collagen stores while promoting formation of new collagen. Figure 5B is a morphometric analysis of the data shown in Figure 5A.

\section{NO-np MODIFIES LEUKOCYTE INFILTRATION IN BURN INJURY INFECTED WITH C. ALBICANS}

We investigated the effect of NO-np on leukocyte migration to the $C$. albicans-infected tissue (Figure 6). First, neutrophil infiltration was evaluated by measuring the production of MPO in the injured area. MPO is an enzyme most abundantly present in neutrophils, and the localized brown staining reaction observed indicated more neutrophil infiltration in NO-np-treated samples compared to untreated or np-treated burn tissue (Figure 6A).

Secondly, we identified macrophage-like infiltration by measuring the expression of Iba-1, which is specifically expressed and upregulated during the activation of these cells. Iba- 1 is the product of the Aif1 gene (allograft inflammatory factor 1) which is located within a segment of the major histocompatibility 


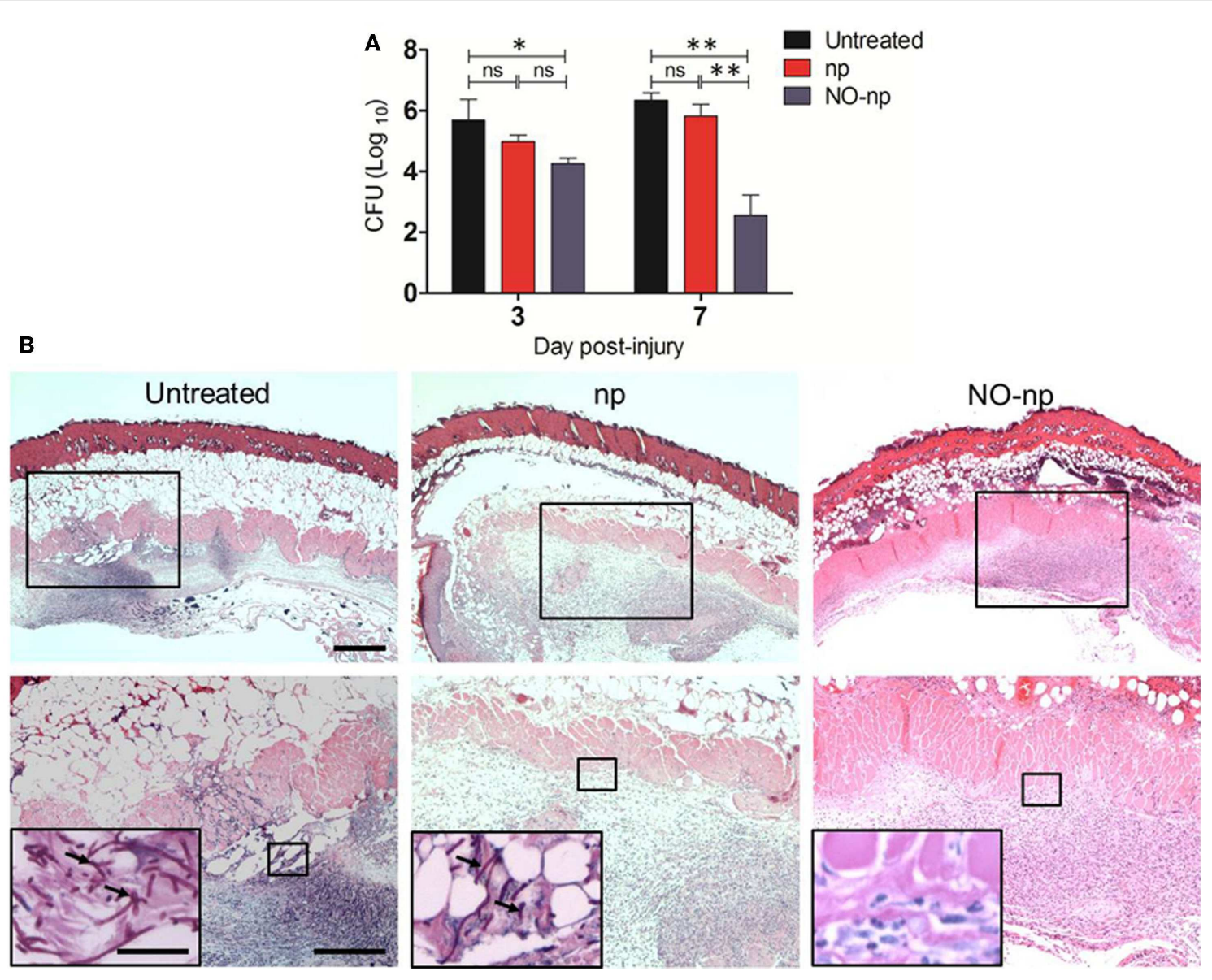

FIGURE 3 | Antifungal efficacy of NO-np in $\boldsymbol{C}$. albicans induced burn infections. (A) Burn fungal burden (colony forming units, CFU) in mice infected topically with $10^{7}$ yeast cells and treated with NO-np is significantly lower than untreated or np-treated mice $(n=5)$. Bars are the averages of the results and brackets denote standard deviations. Asterisks denote $P$ value significance $\left({ }^{*} P<0.05 ;{ }^{*} P<0.001\right.$; ns, no significance) calculated by analysis of variance and adjusted by use of the
Bonferroni correction. (B) Histological analysis of Balb/c mice untreated C. albicans-infected, np-treated C. albicans-infected, and C. albicans-infected treated with NO, day 7. Mice were infected with $10^{7} \mathrm{C}$. albicans. Representative H\&E-stained sections of the skin lesions are shown with the Insets showing Periodic acid schiff staining of $C$. albicans. Black arrows indicate fungal pseudohyphae and hyphae. Scale bars: $20 \mu \mathrm{m}$. complex class III region. Tissue sections from untreated murine burns showed only scattered macrophage-like cells whereas np and NO-np-treated mice showed massive cellular infiltrations into the injured area (Figure 6B).

Together, our data suggests NO-np can stimulate cell recruitment during burn healing and fungal cell clearance by upregulating phagocytic cell infiltration into the injured area.

\section{DISCUSSION}

Candida albicans has emerged as a major agent of hospitalacquired infections and this fungus has a high incidence of progression from focal infection to invasive and/or systemic diseases in specific patient subpopulations such as burn victims (Holzheimer and Dralle, 2002). Our data shows that NO-np interferes with $C$. albicans growth in vitro, which is likely attributable to the sustained release of NO that can penetrate and permeabilize the cellular membrane of yeast cells. The rate and amount of NO released from this nanotechnology allows the free radical to alter peripheral and integral structures on the yeast membrane, particularly membrane-bound proteins and lipids. As a lipophilic and uncharged molecule, NO can easily transverse the lipid bilayer to reach key metabolic enzymes, messenger RNA, proteins, and DNA, disabling vital biological processes (Jones et al., 2010). Furthermore, formation of peroxynitrite from interactions with superoxides further disrupts the yeast membrane through lipid peroxidation, accelerating degradation of cellular integrity. Previous studies suggest that $\mathrm{NO}$ greatly accelerates the rate at which hydrogen peroxide kills microbes by damaging their DNA (Woodmansee and Imlay, 2003). NO also blocks respiration, an event that can stimulate oxidative DNA damage (Woodmansee and Imlay, 2003). Likewise, alterations in cell charge may lead to increased phagocytosis and killing of fungal cells by phagocytes (Nosanchuk and Casadevall, 1997). Recently, we suggested that NO-np is a promising candidate for use in cutaneous infections due to its excellent tissue penetration and potent, broad spectrum antimicrobial activity (Witte et al., 1998; Ghaffari et al., 2006; Martinez 


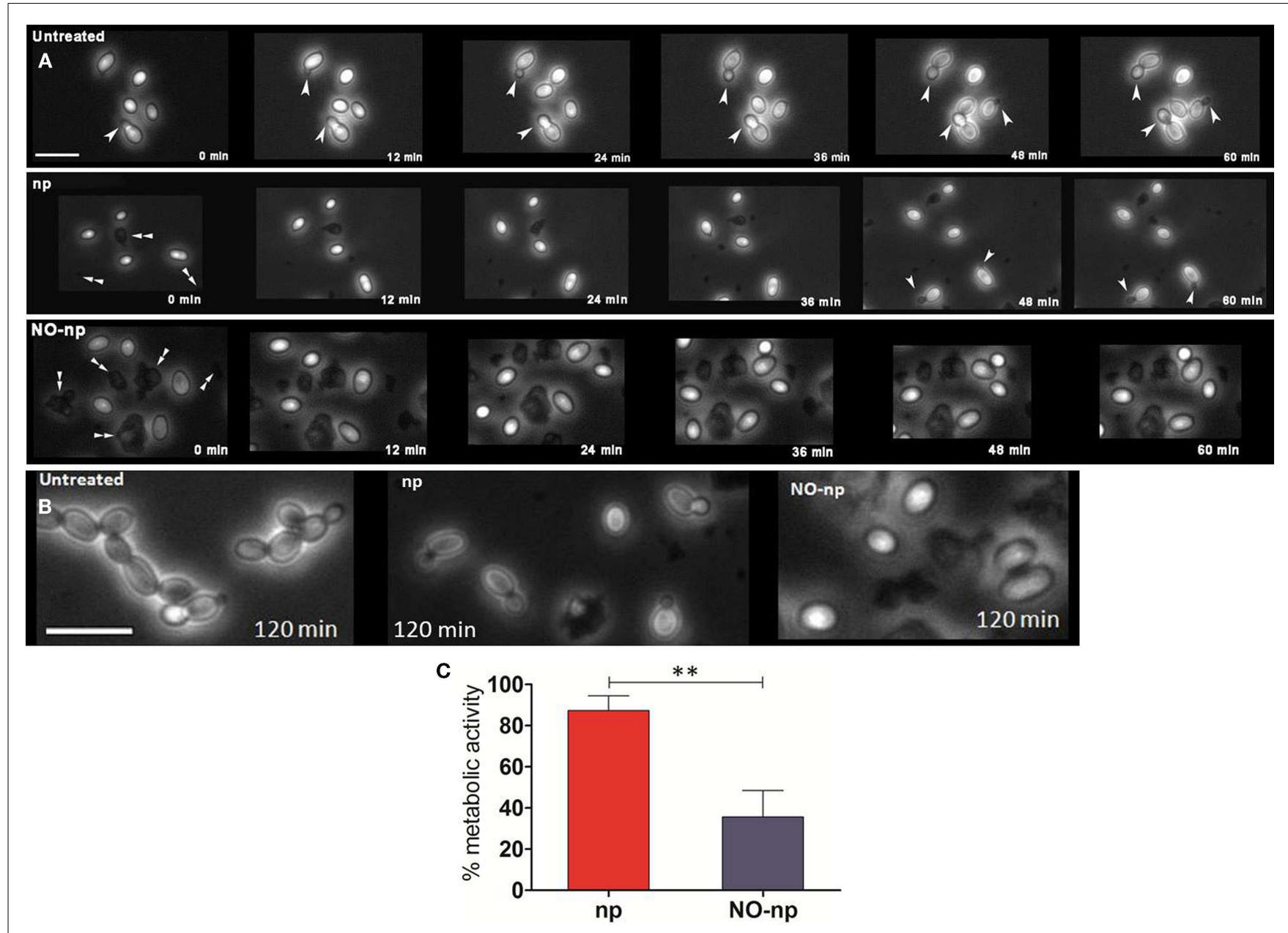

FIGURE 4 | Impact of NO-np on fungal growth and morphogenesis. (A) Time-lapse (0-60 $\mathrm{min}$ ) microscopy was used to explore the effect of NO-np on C. albicans cell division and morphological transformation. White single arrow heads indicate budding yeast and/or pseudohyphae whereas white double arrow heads indicate nanoparticle aggregates. Images were collected at 40x. Scale bar: $10 \mu \mathrm{m}$. (B) Time-lapse microscopy images of untreated, $\mathrm{np}$, and NO-np groups at $120 \mathrm{~min}$. Images collected at 40x. Scale bar: $10 \mu \mathrm{m}$. (C) XTT reduction assay was used to measure the metabolic activity of NO-np-treated filamentous C. albicans in vitro. The $100 \%$ activity was set as the measurements in wells with filamentous fungi without the addition of either NO-np or np. Bars represent the average of the results and error bars denote standard deviations. Asterisks denote $P$ value significance $\left({ }^{*} P<0.001\right)$ calculated by analysis of variance and adjusted by use of the Bonferroni correction. These experiments were performed twice with similar results. et al., 2009). In this regard, NO is able to diffuse through skin and soft tissues thereby reducing the microbial burden.

Our studies demonstrate that NO-np have significant antifungal efficacy in the setting of C. albicans-infected burn injury. Burn injuries and infection can lead to serious complications including tissue damage, sepsis and death. NO-np was found to prevent fungal invasion to the subcutis/muscle and reduced dermal candidal burden. NO also stimulated the infiltration of innate immune cells such as neutrophils and macrophages (Ghaffari et al., 2007), which enhanced its impact as an antifungal agent. NO-np can potentially induce a protective immune response capable of containing infection, therefore preventing systemic dissemination. Additionally, time-lapse microscopy images suggest that NO-np may arrest growth and morphogenesis of C. albicans during infection. The mechanisms underlying these effects of the NO-np on morphogenesis are not yet elucidated, and are likely multi-factorial, potentially impacting adhesion (Privett et al., 2010), colonization (Elahi et al., 2001), tissue penetration (Ghaffari et al., 2006), and dissemination (Glittenberg et al., 2011). The effects of the particles can be as simple as interfering with cell-cell interactions (Netea et al., 2002; Glittenberg et al., 2011) or quorum sensing to disrupting cell signaling cascades (Toenjes et al., 2009) or directly damaging DNA (Woodmansee and Imlay, 2003; Jones et al., 2010). Perhaps, NO-np may directly influence cyclic AMPprotein kinase A complex which is the major pathway by which hyphal growth is regulated in C. albicans (Bahn et al., 2007). This is a promising area for future studies.

NO-np treatment of C. albicans burn injuries offers additional benefits, as we found that treatment results in the stimulation of healing by induction of collagen deposition and/or protects against collagen degradation. NO promotes wound healing by inducing collagen secretion by fibroblasts (Han et al., 2012). Acceleration of 


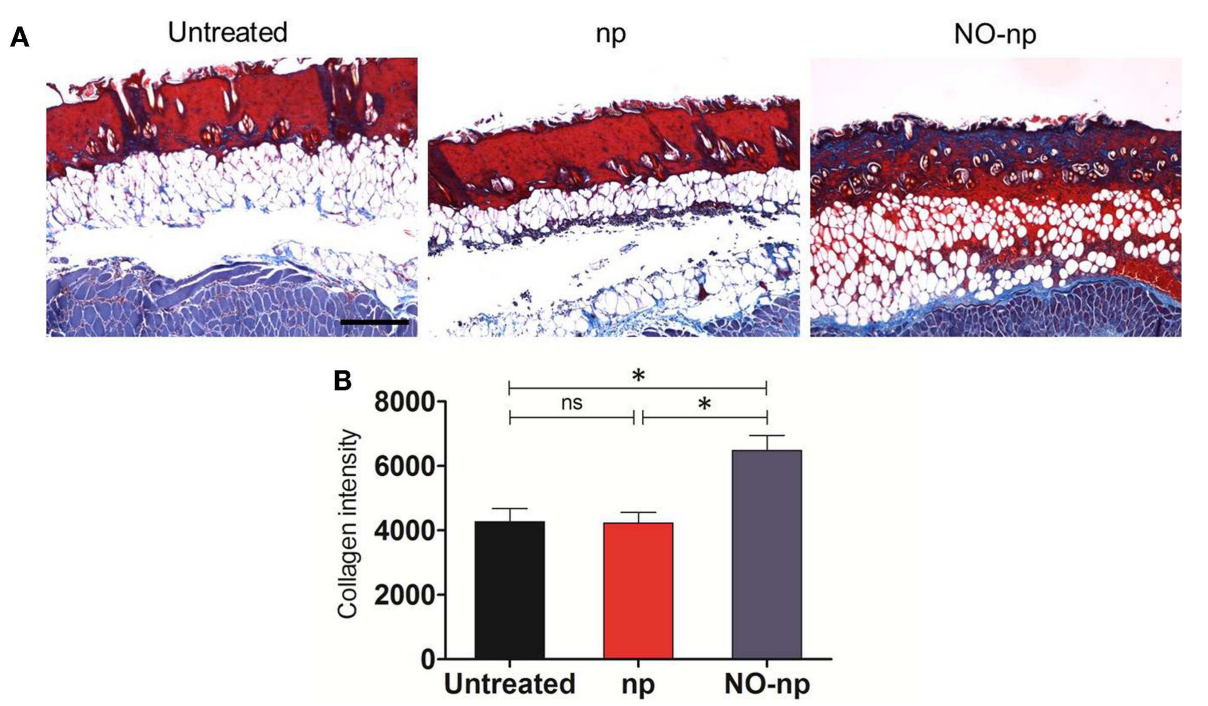

FIGURE 5 | Effect of NO-np on C. albicans collagen degradation in burn injuries. (A) Histological analysis of Balb/c mice untreated $C$. albicans-infected, np-treated C. albicans-infected, and C. albicans-infected treated with NO-np, day 7. Mice were infected with $10^{7}$ fungal cells. The blue stain indicates collagen. Scale bar: $20 \mu \mathrm{m}$. (B) Quantitative measurement of collagen intensity in 20 representative squares of the same size for untreated $C$. albicans-infected, np-treated C. albicans-infected, and $C$. albicans-infected treated with NO-np. Bars are the averages of the results, and error bars denote standard deviations. Asterisks denote $P$ value significance ( ${ }^{*} P<0.05$ ) calculated by analysis of variance and adjusted by use of the Bonferroni correction.

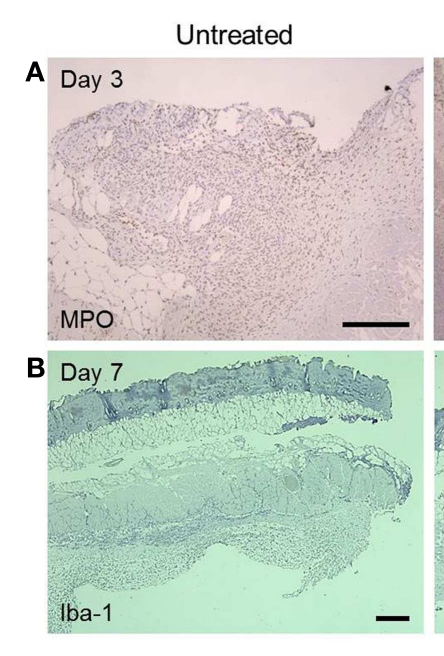

FIGURE 6 | Influence of NO-np on neutrophil and macrophage-like cell infiltration into burn wounds. (A) Histological analysis of untreated, np-treated and NO-np-treated wounded Balb/c mice, day 3. The brown staining indicates neutrophil infiltration. Representative MPO-immunostained sections of the skin lesions are shown. Scale
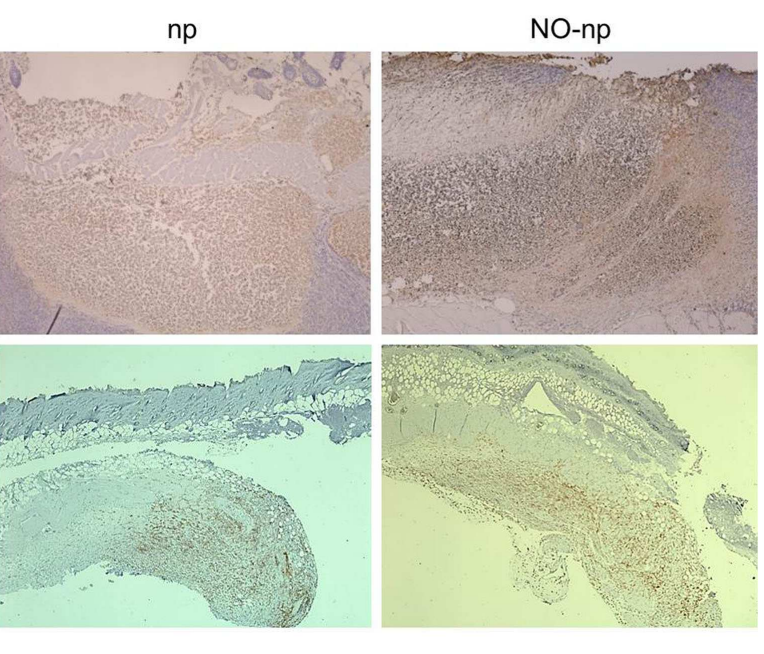

wound healing by nitric oxide donors (Lund and Scholefield, 1997) and NO-np has also been demonstrated recently (Martinez et al., 2009; Han et al., 2012). Indeed, accelerated healing of gastric ulcers has been demonstrated in rats treated with a nitric oxide releasing derivative of diclofenac, and a similar effect was observed by treating the rats with glyceryl trinitrate (Elliott et al., 1995). Further, Thornton et al. (1998) demonstrated that collagen deposition can bars: $20 \mu \mathrm{m}$. (B) Histological analysis of untreated, np-treated and NO-np-treated wounded Balb/c mice, day 7. The brown staining indicates macrophage-like cell infiltration. Representative Iba-1-immunostained sections of the skin lesions are shown. Scale bars: $25 \mu \mathrm{m}$. 
by producing toxic byproducts and competing with cells for oxygen and nutrients (Robson et al., 1990). C. albicans adheres to laminin and fibronectin, types I and IV collagen proteins (Alonso et al., 2001) and releases metalloproteases that degrade collagen (Imbert et al., 2002) which facilitate the migration of the yeast in tissues after crossing the endothelial layer, allowing for fungal invasion of target organs (Rodier et al., 1999). Impeding the metabolic function of microbes diminishes their capacity to damage host tissues.

Concomitant to reducing host damage by injuring invading microbes, NO modifies the host effector response. In addition to their antimicrobial functions, neutrophils are recruited from the blood to sites of inflammation, where they contribute to wound healing (Theilgaard-Monch et al., 2004). Once in the wound environment, neutrophils phagocytose foreign material and bacteria, destroying them by releasing proteolytic enzymes and oxygenderived free radical species. Nevertheless, in the absence of ongoing infection, neutrophil activity gradually changes within a few days of injury to prevent tissue damage. In later stages of healing, the neutrophils must be eliminated from the wound site. Redundant cells are disposed of by extrusion to the wound surface as either slough or by apoptosis, allowing elimination of the entire neutrophil population without further tissue damage or potentiation of the inflammatory response. The cell remnants and apoptotic bodies are then phagocytosed by macrophages. Consistent with this finding we found relatively high numbers of neutrophils in wounds of NO-np-treated mice early on in the infection.

The role of macrophages in wound healing has evolved from the concept that macrophages primarily clear a wound of foreign material, to the understanding that macrophages are involved in multiple aspects ranging from re-epithelialization and collagen deposition to angiogenesis and cell proliferation (Mirza et al., 2009; Friedman, 2011). We use Iba-1, an actin-cross-linking protein expressed in macrophage-like cells but not restricted to the macrophage lineage to investigate the effect of $\mathrm{NO}$ on macrophage-like infiltration in the wound environment. While many studies have focused on the role of macrophage-like cells inducing $\mathrm{NO}$ release from iNOS as part of the host defense, our data suggests that $\mathrm{NO}$ also modulates macrophage-like cell activity, similar to the manner in which NO and VEGF exhibit reciprocal regulation (Kimura and Esumi, 2003; Broughton et al., 2006). We further observed in our study that macrophage migration is

\section{REFERENCES}

Alonso, R., Llopis, I., Flores, C., Murgui, A., and Timoneda, J. (2001). Different adhesins for type IV collagen on Candida albicans: identification of a lectin-like adhesin recognizing the 7S(IV) domain. Microbiology $147(\mathrm{Pt}$ 7), 1971-1981.

Bahn, Y. S., Molenda, M., Staab, J. F., Lyman, C. A., Gordon, L. J., and Sundstrom, P. (2007). Genome-wide transcriptional profiling of the cyclic AMP-dependent signaling pathway during morphogenic transitions of Candida albicans. Eukaryotic Cell 6, 2376-2390.
Baroli, B., Ennas, M. G., Loffredo, F., Isola, M., Pinna, R., and LópezQuintela, M. A. (2007). Penetration of metallic nanoparticles in human full-thickness skin. J. Invest. Dermatol. 127, 1701-1712.

Broughton, G. I. I., Janis, J. E., and Attinger, C. E. (2006). The basic science of wound healing. Plast. Reconstr. Surg. 117(Suppl. 7), 12S-34S.

Cabrales, P., Han, G., Nacharaju, P., Friedman, A. J., and Friedman, J. M. (2011). Reversal of hemoglobininduced vasoconstriction with sustained release of nitric oxide. Am.

increased in NO-np-treated mice suggesting that $\mathrm{NO}$ is a wideacting, critical molecule in the early and late stages of tissue repair and regeneration.

Safety and toxicity of nanotechnology have been well documented and widely discussed (Service, 2003; Nel et al., 2006). Numerous investigations have revealed that diverse nanomaterials can penetrate intact skin in animal models and in human ex vivo models (Gamer et al., 2006; Baroli et al., 2007). Furthermore, cutaneous penetration of NO-np can be enhanced depending on the delivery vehicle used or barrier disruption found, especially this is true in cases of open wounds, such as those that we describe in this study. Of greater concern are toxicities caused by the systemic penetration and ultimate circulation of specific nanomaterials through various orifices, and which have been shown to occur (Hohr et al., 2002). We have demonstrated in vitro that NO-nps show minimal toxicity toward cultured fibroblasts (Friedman et al., 2008). Furthermore, in in vivo safety (murine) evaluations using intraperitoneal and intravenous administration routes minimal cytotoxicity was found with no clinical adverse events occurring in the treated mice (Cabrales et al., 2010, 2011).

In summary, this study shows that NO-np have both antifungal and burn healing properties. Overall, the results presented show that the topical application of NO-np is highly effective against cutaneous C. albicans infection in a murine burn model. In addition, the NO-np appears to enhance burn healing by shielding dermal structural components, such as collagen from degradation, and likely stimulates new collagen generation and deposition. These findings support other studies, which have shown that topically applied NO-np can be effective in inducing a local immune response with minimal inflammation (Mowbray et al., 2009), further adding to its beneficial effects in this application. These results suggest that this platform has the potential to serve as an easily administered source of anti-infectives, such as NO, for the treatment of cutaneous and tissue infections, including those resulting from burn injuries.

\section{ACKNOWLEDGMENTS}

Joshua D. Nosanchuk is supported in part by an Irma T. Hirschl/Monique Weill-Caulier Trust Research award. Luis R. Martinez gratefully acknowledges support from NIH-NIAID 1K22A1087817-01A1 and LIU-Post-Faculty Committee Research awards. Adam J. Friedman gratefully acknowledges support from the Dermatology Foundation.

J. Physiol. Heart Circ. Physiol. 300, H49-H56.

Cabrales, P., Han, G., Roche, C., Nacharaju, P., Friedman, A. J., and Friedman, J. M. (2010). Sustained release nitric oxide from long-lived circulating nanoparticles. Free Radic. Biol. Med. 49, 530-538.

Eggimann, P., Garbino, J., and Pittet, D. (2003a). Management of Candida species infections in critically ill patients. Lancet. Infect. Dis. 3, 772-785.

Eggimann, P., Hugonnet, S., Sax, H., Touveneau, S., Chevrolet, J. C., and Pittet, D. (2003b). Ventilatorassociated pneumonia: caveats for benchmarking. Intensive Care Med. 29, 2086-2089.

Elahi, S., Pang, G., Ashman, R. B., and Clancy, R. (2001). Nitric oxide-enhanced resistance to oral candidiasis. Immunology 104, 447-454.

Elliott, S. N., McKnight, W., Cirino, G., and Wallace, J. L. (1995). A nitric oxide-releasing nonsteroidal anti-inflammatory drug accelerates gastric ulcer healing in rats. Gastroenterology 109, 524-530. 
Frank, S., Kämpfer, H., Wetzler, C., and Pfeilschifter, J. (2002). Nitric oxide drives skin repair: novel functions of an established mediator. Kidney Int. $61,882-888$.

Friedman, A. (2011). Wound healing: from basic science to clinical practice and beyond. J. Drugs Dermatol. $10,427-433$.

Friedman, A., Blecher, K., Sanchez, D., Tuckman-Vernon, C., Gialanella, P., Friedman, J. M., Martinez, L. R., and Nosanchuk, J. D. (2011). Susceptibility of Gram-positive and negative bacteria to novel nitric oxide-releasing nanoparticle technology. Virulence 2, 217-221.

Friedman, A. J., Han, G., Navati, M. S., Chacko, M., Gunther, L., Alfieri, A., and Friedman, J. M. (2008). Sustained release nitric oxide releasing nanoparticles: characterization of a novel delivery platform based on nitrite containing hydrogel/glass composites. Nitric Oxide 19, 12-20.

Gamer, A. O., Leibold, E., and van Ravenzwaay, B. (2006). The in vitro absorption of microfine zinc oxide and titanium dioxide through porcine skin. Toxicol. In vitro 20, 301-307.

Ghaffari, A., Jalili, R., Ghaffari, M., Miller, C., and Ghahary, A. (2007). Efficacy of gaseous nitric oxide in the treatment of skin and soft tissue infections. Wound Repair Regen. 15, 368-377.

Ghaffari, A., Miller, C. C., McMullin, B., and Ghahary, A. (2006). Potential application of gaseous nitric oxide as a topical antimicrobial agent. Nitric Oxide 14, 21-29.

Glittenberg, M. T., Kounatidis, I., Christensen, D., Kostov, M., Kimber, S., Roberts, I., and Ligoxygakis, P. (2011). Pathogen and host factors are needed to provoke a systemic host response to gastrointestinal infection of Drosophila larvae by Candida albicans. Dis. Model Mech. 4, 515-525.

Han, G., Martinez, L. R., Mihu, M. R., Friedman, A. J., Friedman, J. M., and Nosanchuk, J. D. (2009). Nitric oxide releasing nanoparticles are therapeutic for Staphylococcus aureus abscesses in a murine model of infection. PLoS ONE 4(11): e7804. doi:10.1371/journal.pone.0007804.

Han, G., Nguyen, L. N., Macherla, C., Chi, Y., Friedman, J. M., Nosanchuk, J. D., and Martinez, L. R. (2012). Nitric oxide releasing nanoparticles accelerate wound healing by promoting fibroblast migration and collagen deposition. Am. J. Pathol. 180, 1465-1473.

Hohr, D., Steinfartz, Y., Schins, R. P., Knaapen, A. M., Martra, G., Fubini,
B., and Borm, P. J. (2002). The surface area rather than the surface coating determines the acute inflammatory response after instillation of fine and ultrafine $\mathrm{TiO} 2$ in the rat. Int. J. Hyg. Environ. Health 205, 239-244.

Holzheimer, R. G., and Dralle, H. (2002). Management of mycoses in surgical patients - review of the literature. Eur. J. Med. Res. 7, 200-226.

Imbert, C., Kauffmann-Lacroix, C., Daniault, G., Jacquemin, J. L., and Rodier, M. H. (2002). Effect of matrix metalloprotease inhibitors on the $95 \mathrm{kDa}$ metallopeptidase of Candida albicans. J. Antimicrob. Chemother. 49, 1007-1010.

Jones, M. L., Ganopolsky, J. G., Labbé, A., Wahl, C., and Prakash, S. (2010). Antimicrobial properties of nitric oxide and its application in antimicrobial formulations and medical devices. Appl. Microbiol. Biotechnol. $88,401-407$.

Kimura, H., and Esumi, H. (2003). Reciprocal regulation between nitric oxide and vascular endothelial growth factor in angiogenesis. Acta Biochim. Pol. 50, 49-59.

Lund, J. N., and Scholefield, J. H. (1997). Glyceryl trinitrate is an effective treatment for anal fissure. Dis. Colon Rectum 40, 468-470.

Martinez, L. R., Han, G., Chacko, M., Mihu, M. R., Jacobson, M., Gialanella, P., Friedman, A. J., Nosanchuk, J. D., and Friedman, J. M. (2009). Antimicrobial and healing efficacy of sustained release nitric oxide nanoparticles against Staphylococcus aureus skin infection. J. Invest. Dermatol. 129, 2463-2469.

Mihu, M. R., Sandkovsky, U., Han, G., Friedman, J. M., Nosanchuk, J. D., and Martinez, L. R. (2010). The use of nitric oxide releasing nanoparticles as a treatment against Acinetobacter baumannii in wound infections. Virulence 1, 62-67.

Mirza, R., DiPietro, L. A., and Koh, T. J. (2009). Selective and specific macrophage ablation is detrimental to wound healing in mice. Am. J. Pathol. 175, 2454-2462.

Mowbray, M., McLintock, S., Weerakoon, R., Lomatschinsky, N., Jones, S., Rossi, A. G., and Weller, R. B. (2009). Enzyme-independent NO stores in human skin: quantification and influence of UV radiation. J. Invest. Dermatol. 129, 834-842.

Mowbray, M., Tan, X., Wheatley, P. S., Rossi, A. G., Morris, R. E., and Weller, R. B. (2008). Topically applied nitric oxide induces T-lymphocyte infiltration in human skin, but minimal inflammation. J. Invest. Dermatol. $128,352-360$.
Nel, A., Xia, T., Mädler, L., and Li, N. (2006). Toxic potential of materials at the nanolevel. Science 311, 622-627.

Netea, M. G., Meer, J. W., Verschueren, I., and Kullberg, B. J. (2002). CD40/CD40 ligand interactions in the host defense against disseminated Candida albicans infection: the role of macrophage-derived nitric oxide. Eur. J. Immunol. 32, 1455-1463.

Nosanchuk, J. D., and Casadevall, A. (1997). Cellular charge of Cryptococcus neoformans: contributions from the capsular polysaccharide, melanin, and monoclonal antibody binding. Infect. Immun. 65 , 1836-1841.

Privett, B. J., Nutz, S. T., and Schoenfisch, M. H. (2010). Efficacy of surface-generated nitric oxide against Candida albicans adhesion and biofilm formation. Biofouling 26, 973-983.

Qi, L., Xu, Z., Jiang, X., Hu, C., and Zou, X. (2004). Preparation and antibacterial activity of chitosan nanoparticles. Carbohydr. Res. 339, 2693-2700.

Robson, M. C., Stenberg, B. D., and Heggers, J. P. (1990). Wound healing alterations caused by infection. Clin. Plast. Surg. 17, 485-492.

Rodier, M. H., el Moudni, B. Kauffmann-Lacroix, C., Daniault, G., and Jacquemin, J. L. (1999). A Candida albicans metallopeptidase degrades constitutive proteins of extracellular matrix. FEMS Microbiol. Lett. 177, 205-210.

Santucci, S. G., Gobara, S., Santos, C. R., Fontana, C., and Levin, A. S. (2003). Infections in a burn intensive care unit: experience of seven years. $J$. Hosp. Infect. 53, 6-13.

Schairer, D., Martinez, L. R., Blecher, K., Chouake, J., Nacharaju, P., Gialanella, P., Friedman, J. M., Nosanchuk, J. D., and Friedman, A. J. (2012). Nitric oxide nanoparticles: pre-clinical utility as a therapeutic for intramuscular abscesses. Virulence 3, 62-67.

Service, R. F. (2003). American chemical society meeting. Nanomaterials show signs of toxicity. Science 300 , 243.

Soneja, A., Drews, M., and Malinski, T. (2005). Role of nitric oxide, nitroxidative and oxidative stress in wound healing. Pharmacol. Rep. 57(Suppl.), 108-119.

Theilgaard-Monch, K., Knudsen, S., Follin, P., and Borregaard, N. (2004). The transcriptional activation program of human neutrophils in skin lesions supports their important role in wound healing. J. Immunol. 172, 7684-7693.
Thornton, F. J., Schäffer, M. R., Witte, M. B., Moldawer, L. L., MacKay, S. L., Abouhamze, A., Tannahill, C. L., and Barbul, A. (1998). Enhanced collagen accumulation following direct transfection of the inducible nitric oxide synthase gene in cutaneous wounds. Biochem. Biophys. Res. Commun. 246, 654-659.

Tillmann, A., Gow, N. A., and Brown, A. J. (2011). Nitric oxide and nitrosative stress tolerance in yeast. Biochem. Soc. Trans. 39, 219-223.

Toenjes, K. A., Stark, B. C., Brooks, K. M., and Johnson, D. I. (2009). Inhibitors of cellular signalling are cytotoxic or block the budded-tohyphal transition in the pathogenic yeast Candida albicans. J. Med. Microbiol. 58(Pt 6), 779-790.

Ullmann, B. D., Myers, H., Chiranand, W., Lazzell, A. L., Zhao, Q., Vega, L. A., Lopez-Ribot, J. L., Gardner, P. R., and Gustin, M. C. (2004). Inducible defense mechanism against nitric oxide in Candida albicans. Eukaryotic Cell 3, 715-723.

Witte, M. B., Thornton, F. J., Kiyama, T., Efron, D. T., Schulz, G. S., Moldawer, L. L., and Barbul, A. (1998). Metalloproteinase inhibitors and wound healing: a novel enhancer of wound strength. Surgery 124, 464-470.

Woodmansee, A. N., and Imlay, J. A. (2003). A mechanism by which nitric oxide accelerates the rate of oxidative DNA damage in Escherichia coli. Mol. Microbiol. 49, $11-22$.

Conflict of Interest Statement: Adam J. Friedman and Joshua D. Nosanchuk are scientific advisors and hold stock options in Makefield Therapeutics.

Received: 08 February 2012; accepted: 11 May 2012; published online: 08 June 2012.

Citation: Macherla C, Sanchez DA, Ahmadi MS, Vellozzi EM, Friedman $A J$, Nosanchuk JD and Martinez LR (2012) Nitric oxide releasing nanoparticles for treatment of Candida albicans burn infections. Front. Microbio. 3:193. doi: 10.3389/fmicb.2012.00193

This article was submitted to Frontiers in Fungi and Their Interactions, a specialty of Frontiers in Microbiology.

Copyright (0) 2012 Macherla, Sanchez, Ahmadi, Vellozzi, Friedman, Nosanchuk and Martinez. This is an open-access article distributed under the terms of the Creative Commons Attribution Non Commercial License, which permits noncommercial use, distribution, and reproduction in other forums, provided the original authors and source are credited. 